\title{
Protection of Ecosystem and Preservation of Biodiversity: The Geospatial Technology Approach
}

\author{
Ogunlade S. O. \\ Department of Surveying and Geoinformatics, Federal University of Technology, Akure, Nigeria \\ Corresponding Author: soogunlade@futa.edu.ng
}

https://doi.org/10.36263/nijest.2021.01.0253

\begin{abstract}
The protection of ecosystem and preservation of biodiversity through the approach of geospatial technology was the aim of this research. The channel was monitoring the spatial transformation of the Federal University of Technology, Akure, Nigeria between year 2002 and year 2018 using Satellite Remote Sensing and Geographical Information System techniques. Landsat 7 Enhanced Thematic Mapper (ETM) plus of year 2002, Landsat 8 Operational Land Imager (OLI) and Thermal Infrared Sensor (TIRS) of year 2014 and year 2018 all of $32 \mathrm{~m}$ resolution were the satellite images obtained for the study. These images were processed with supervised maximum likelihood classification algorithm using ArcGIS 10.3 software. To validate the classification and ensure high accuracy, an accuracy assessment was performed using training samples from 60 points on each of the satellite imagery on a reference image from google earth combined with ground data collected on actual visitation to the study area to verify the true land-cover type existing on the site. The resultant images deemed fit for analyses were classified into built-up, thick vegetation, light vegetation and bare land, land cover classes. Microsoft Excel spreadsheet was used to perform land cover area calculations through which the land cover dynamics and the spatial expansion were identified. The result showed built-up $(13.58 \%, 14.59 \%, 20.75 \%)$; thick vegetation $(33.78 \%$, $26.26 \%, 12.18 \%)$; Light vegetation $(24.57 \%, 32.29 \%, 30.51 \%)$; Bare land $(28.08 \%, 26.26 \%$, $36.56 \%)$ for the three years respectively. A special focus was put on the general depletion of the (thick and light) vegetation of which trees are a major actor. This depletion was adduced to the positive transformation of other land cover classes through the underlining landuse. The study concluded that alteration, depletion and consequent disappearance of trees in the green ecosystem is a threat to environment's sustainability and the protection of ecosystem and preservation of biodiversity. The study recommended the research as a tool to controlling the removal of trees and thick forest, growing more trees and plants among other factors to protect ecosystem and preserve biodiversity.
\end{abstract}

Keywords: Ecosystem, Geospatial Technology, Land cover, Land use, Satellite Images

\subsection{Introduction}

Jamie (2019), United Nations (2020) Szaro et al. (1998) affirmed the protection of the ecosystem and preservation of biodiversity as inevitable in the sustainability of the ever dynamic environment, and as an all-important concern of the global sustainable development agenda, thus requiring the attention of the research world. The duos are two inseparable twin-concern of the United Nation (UN) in the quest to transform the world by the year 2030 and beyond. According to Caballero (2016), the global Sustainable Development Goals (SDGs) or "2030 Agenda" (2015-2030) is a clarion call to all developing and developed countries to partner globally to achieve sustainable developments by the year 2030. The quest began as millennium development goals (MDGs) in 2000 and supposed to attain full achievement by 2015 (United Nations, 2015) but got further extended as sustainable development goals (SDGs) to year 2030 (Caballero, 2016). In the environmental management part of these global goals; sustainable landscape development constitutes an important transition pathway to the SDGs (United Nations, 2017). Embedded in the sustainable landscape development are the inevitable protection of the ecosystem and the preservation of biodiversity (United Nations, 2020). Ogunlade $(2018 \mathrm{~b} ; 2020 \mathrm{a})$ attested that in the transition to and actualization of sustainable development goals the 
geospatial environment remains a major player. The environment is ever dynamic and the monitoring of the dynamics remains a crucial pathway in the transition (Ogunlade, 2018a). Spatial dynamics according to Ogunlade (2019), Igbokwe et al. (2016) is an important factor in the sustainability of of the environment. The indicator of the dynamics of the environment is the land use land cover change (Lackey, 1998). Hence, through the measurement of the LULC transformation, spatial expansion are monitored thus the ecosystem and biodiversity are well managed. In the ecosystem, there is a communal systemic interaction between living organisms (plants and animals) and their environment non-living components. The interactions are mainly on the terrestrial or aquatic platforms. The terrestrial interaction can be in the form of green (forest, grassland), tundra, and desert ecosystems; while the aquatic platform is either in form of fresh water or marine ecosystems. Management of the ecosystem is a salient in getting the best of the natural resources. Ecosystem resilience and sustainability, and its constant evaluation are inevitable in its protection and in the preservation of biodiversity (Meffe et al., 2013; Szaro et al., 1998; United Nations, 2020). The role and supremacy of geospatial technology in measuring and monitoring the earth surface have become so germane in the modern days primarily due to advent of computers, advancement in technology through availability of sophisticated digital instrument and highly researched and innovated methodologies (Ogunlade, 2020b). In-depth multifaceted discovery, large volume of data acquisition and management, speedy multipurpose transformation of data, diversified high level applications are some of the benefits of the involvement of geospatial technology in the management of the environment and the ecosystem (Oyinloye et al., 2018). Integration of Satellite Remote Sensing and GIS techniques has excelled in the recent times above conventional techniques for speed, coverage and unlimited reach Ogunlade (2018a, 2018b). Thus, this research premised on the rich profitability of geospatial technology to monitor and evaluate the protection of the green ecosystem and preservation of biodiversity from the view point of land use land cover dynamics of the study area.

\subsection{Materials and Methods}

Satellite images of Ondo state (Landsat ETM+ 2002, Landsat OLI/TIRS 2014, and Landsat OLI/TIRS 2018) downloaded from U.S. Geological Survey.; the boundary map of the study area from Surveying Department Federal University of Technology Akure Nigeria; and coordinates of ground control points through dual frequency Global Navigation Satellite System (GNSS) survey from the study area, were the materials obtained for the research. The satellite imageries were all subjected to algorithms of geometric and radiometric correction in ArcGIS 10.3 software environment. The boundary map of the study area was in AUTOCAD format (.dwg file) and was converted to shape-file (.shp) in the ArcGIS 10.3 environment and used to clip out the study area from the satellite imagery. To enhance visualization of features in the imagery, creation of false colour composite images was performed using ArcGIS 10.3 (Figure 1) by the combination of Near Infrared (NIR), Red (R) and Green $(\mathrm{G})$ bands of each imagery (Table 1$)$.

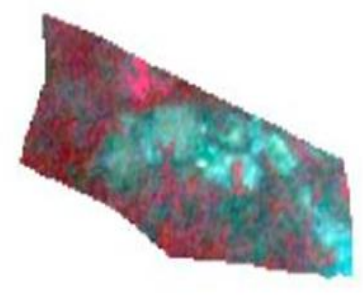

(a.)2002 image

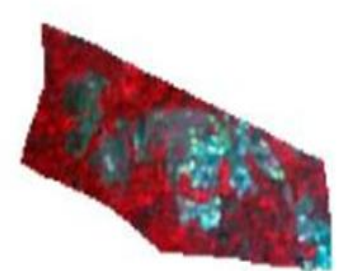

(b.) 2014 image

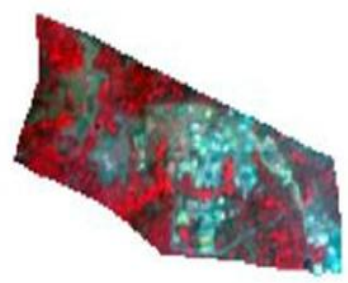

(c.) 2018 image

Figure 1: False colour composite for each year of study

Table 1: Landsat band combinations.

\begin{tabular}{llll}
\hline Image & 2002 (Landsat 7 ETM+) & 2014 Landsat 8 (OLI/TIRS) & 2018 Landsat 8 (OLI/TIRS) \\
\hline Spectral Band Combination & $4,3,2$ & $5,4,3$ & $5,4,3$ \\
Spectral Band Names & NIR, Red, Green & NIR, Red, Green & NIR, Red, Green \\
\hline
\end{tabular}

To further enhance visualization of features in the composite images, ESRI pan-sharpening method in ArcGIS 10.3 was performed on the composite images by fusing the higher-resolution panchromatic $8^{\text {th }}$ band of each Landsat image with the low spatial resolution composite image. 
The image classification was performed using supervised classification with maximum likelihood. The images were classified under the following four classes in Table 2.

Table 2: Showing the LULC classes and description

\begin{tabular}{ll}
\hline LULC classes & Description \\
\hline Built up Areas & $\begin{array}{l}\text { Residential (staff quarters and student hostels), academic and administrative } \\
\text { buildings, commercial centres, all other levels of housing }\end{array}$ \\
Thick vegetation & Heavy green areas, thick forest and trees. \\
Light vegetation & $\begin{array}{l}\text { Grassland, horticultural gardens, farmlands, vegetated open spaces } \\
\text { Bare land }\end{array}$ \\
\hline
\end{tabular}

To validate the classification and ensure high accuracy, an accuracy assessment was performed to compare the classified image to what actually obtained on the ground. Training samples from 60 points on the each of the satellite imagery were used on a reference image from Google earth combined with ground troth data collected on actual visitation to the study area to verify the true landcover type existing on the site. The ground troth data was compared with the classified image and it was discovered to have relatively matched with what was obtainable on the image. The high number of training samples was chosen due to the fact that the areal extent being studied is small, hence the need for more training sample to ensure a high accuracy of classification. The size of the study area helped in actual visitation for on-the-site verification.

\subsection{Land cover/use Area Calculation}

After image classification, the area covered by each LULC class was calculated with Microsoft Excel spreadsheet using the formula:

$A=\frac{C_{t} \cdot C_{s}^{2}}{10000}$

where:

A Areal extent of each LULC class in Hectares

$C_{t} \quad$ COUNT, the number of pixels in a LULC class. The COUNT value for each class was obtained from the attribute table of the classified map.

$C_{S} \quad$ Cell size of the classified image for each year, which was $15 \mathrm{~m}$ by $15 \mathrm{~m}$.

\subsection{Results and Discussions}

Four land cover classes were generated from the supervised image classification performed (Table 2). The areal extent for each land cover class in each year was calculated using Microsoft Excel spreadsheet and tabulated (Table 3). The corresponding landuse/landcover (LULC) maps were generated for the year 2002 (Figure 3), 2014 (Figure 4) and 2018 (Figure 5). The transformation that occurred within the LULC classes in the epochs of study was calculated (Table 4).

Table 3: Areal extent of LULC classes

\begin{tabular}{lllllll}
\hline Year & \multicolumn{2}{c}{2002} & \multicolumn{2}{c}{2014} & \multicolumn{2}{c}{2018} \\
\hline LULC Type & \multicolumn{5}{c}{ Areal extent } \\
\cline { 2 - 7 } & $(\mathrm{Ha})$ & $(\%)$ & $(\mathrm{Ha})$ & $(\%)$ & $(\mathrm{Ha})$ & $(\%)$ \\
\hline Built Up & 78.48 & 13.58 & 84.33 & 14.59 & 119.90 & 20.75 \\
Bare Land & 162.25 & 28.08 & 151.76 & 26.26 & 211.25 & 36.56 \\
Thick Veg. & 195.19 & 33.78 & 155.21 & 26.86 & 70.40 & 12.18 \\
Light Veg & 141.98 & 24.57 & 186.59 & 32.29 & 170.33 & 30.51 \\
Total & 577.89 & 100.00 & 577.89 & 100 & 577.89 & 100 \\
\hline
\end{tabular}


Table 4: LULC Transformations in two epochs

\begin{tabular}{llllll}
\hline Year & 2002 & \multicolumn{4}{c}{2014} \\
\hline LULC Type & \multicolumn{5}{c}{ Areal Extent } \\
\cline { 2 - 6 } & $(\%)$ & $\Delta \%$ & $(\%)$ & $\Delta \%$ & $(\%)$ \\
\hline Built Up & 13.58 & 1.01 & 14.59 & 6.16 & 20.75 \\
Bare Land & 28.08 & -1.82 & 26.26 & 10.3 & 36.56 \\
Thick Veg. & 33.78 & -6.92 & 26.86 & -14.68 & 12.18 \\
Light Veg & 24.57 & 7.72 & 32.29 & -1.78 & 30.51 \\
\hline
\end{tabular}

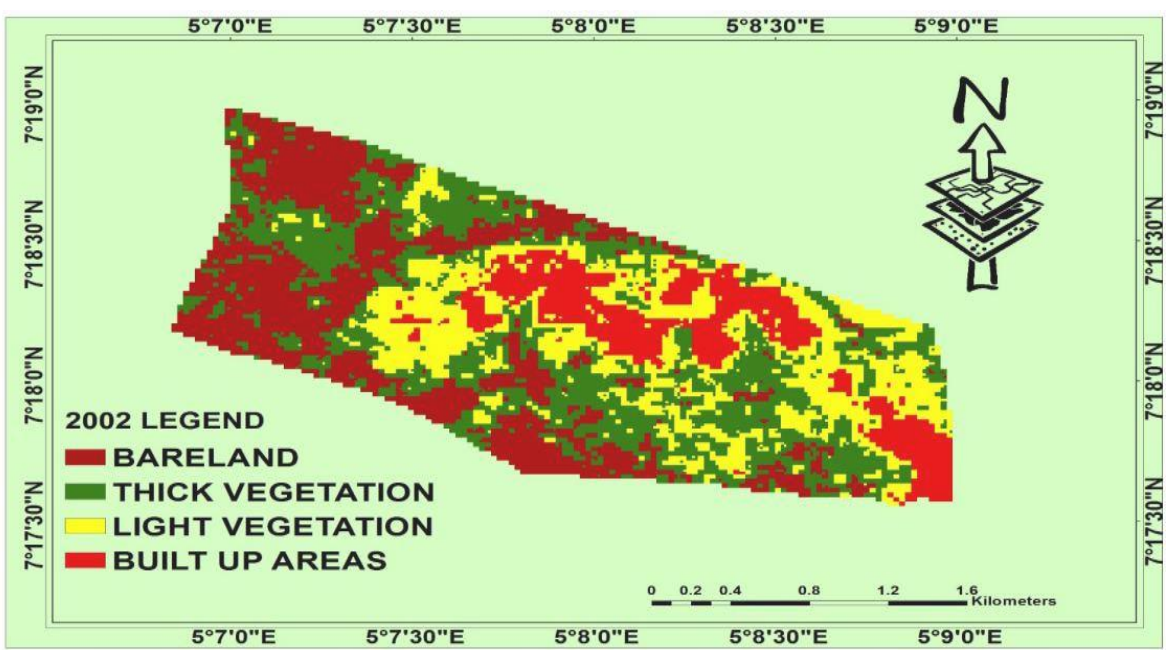

Figure 3: Land use/Land cover map of FUTA in 2002

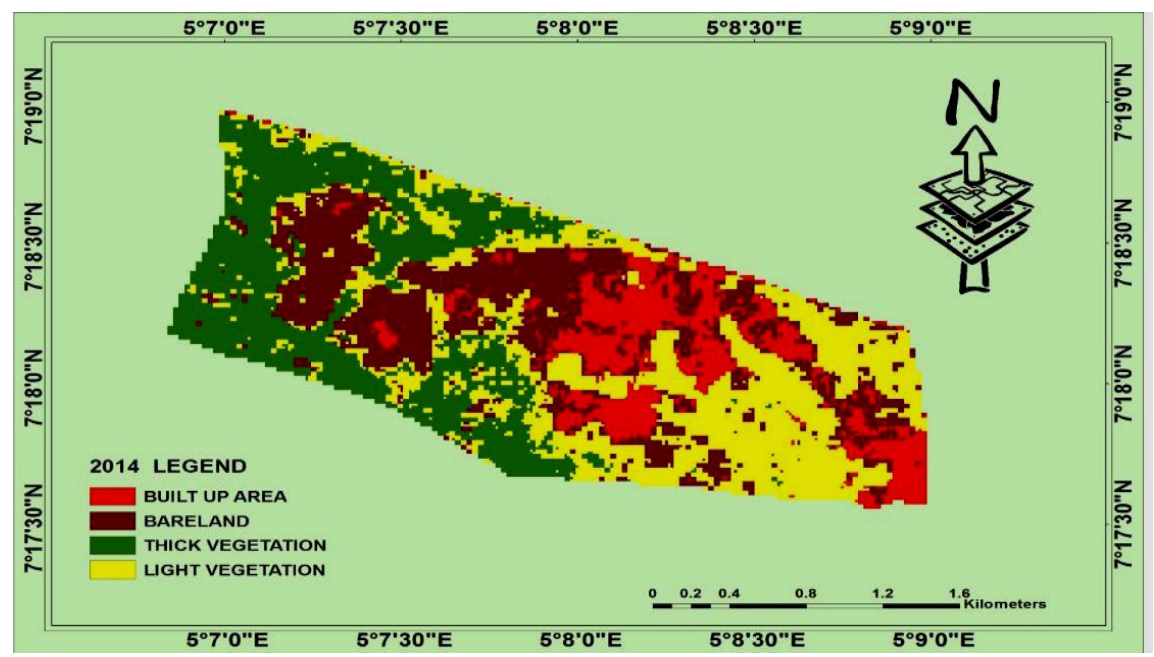

Figure 4: Land use/Land cover map of FUTA in 2014

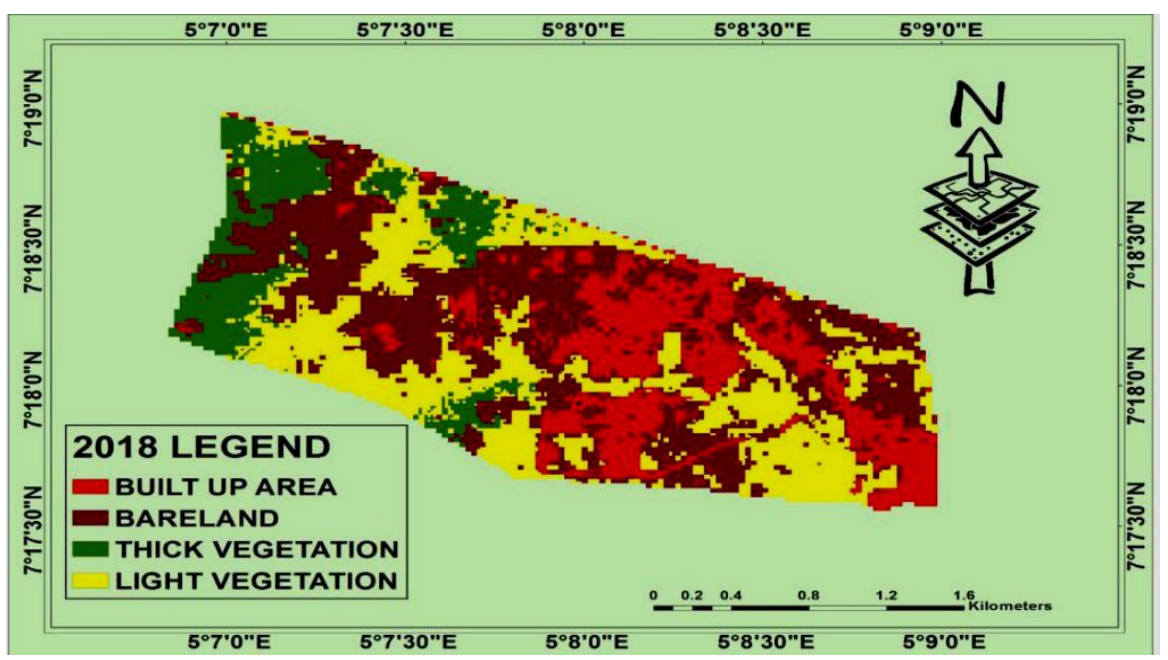

Figure 5: Land use/Land cover map of FUTA in 2018 
The transformation in the land cover classes for the two epochs in Table 4 showed that Built-Up and Bare Land classes had an appreciable gain of $7.17 \%$ and $8.48 \%$ respectively. These are all at the expense of the thick forest with an overall loss of $21.8 \%$. Light vegetation has commenced depletion by $1.78 \%$ in the second epoch. The overall perception is shown in Figure 6 and the transformation of individual land cover class is shown in Figure 7.

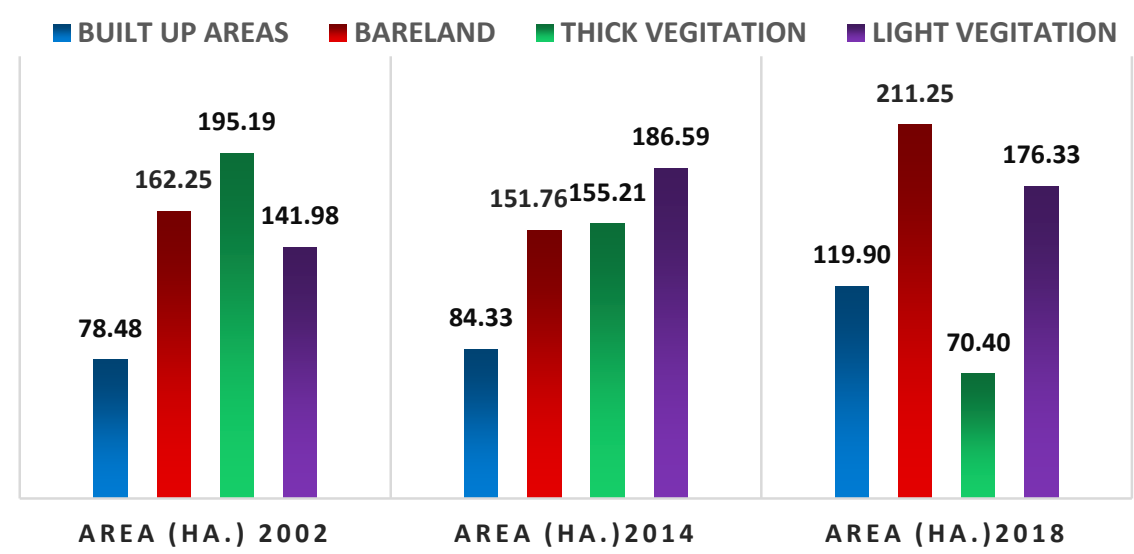

Figure 6: Overall view of the land cover transformation in the two epochs

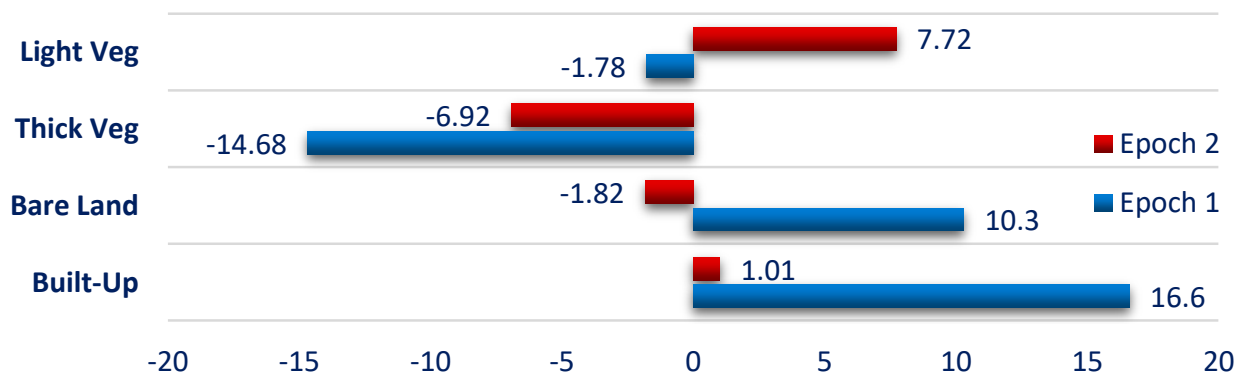

Figure 7: Individual land cover transformation

Observation in Figure 7 showed that the green ecosystem (vegetation land cover) is suffering the overall loss. There was a reduction of the light vegetation to -1.78 between 2014 and 2018, a space of four years. Worse still the thick vegetation depleted by a lump sum of $14.68 \%$ within a space of four years! All these are ripple effect of positive transformation of other land cover through the underlining landuse (Ogunlade 2018a). The ripple effect majorly affects the thick forest (trees) which are being lost at very alarming rate!

\subsection{Effect of vegetation (green ecosystem) loss on the Ecosystem and Biodiversity}

Szaro et al. (1998); Lackey (1998); Meffe et al. (2013) attested that humans are the life wire and the colour of the ecosystem. NC State University (2021), Precision Land Scape and Trees (2021), Keystone Ten Million Trees Partnership (2021) observed that plants are a carbon-sink in the ecosystem as they absorb carbon dioxide released by man and release oxygen that is highly needed for the survival of man. According to the findings of Treepeople (2020), UNFAO (2016) research has shown that a single tree can absorb up to $150 \mathrm{~kg}$ (330lb) of $\mathrm{CO}_{2}$ in a year. Thus plants reduce carbon emission. A deficiency in the plant-man carbon-sink flow amounts to danger for the man such as illhealth, social vices, and even death. Russell (2014), Christopher (2019), Precision Land Scape and Trees (2021) observed that man do experience more stress due to harsh weather as climate change are escalated by atmospheric pollutants.

Absence of green ecosystem makes stress to sky rocket. Christopher (2019) revealed that from research into magnetic resonance imaging (MRI) scan, cities and natural features receives different perception in our brains. He explained that while cities are found in the part of the brain responsible 
for hostile environments, natural features are found in the part of the brain responsible for empathy and compassion. Thus, according to INSH (2018) the presence of the green ecosystem regulates the brain's hostile perception of the city's harsh environment in city inhabitants thereby cushioning the inevitable anxiety, depression and aggression in an already violent, de-stabilized world.

The loss of the green ecosystem will make the city environment louder. Szaro et al. (1998); Lackey (1998); Meffe et al. (2013) attested that trees are good absorber of sound waves. Thus trees and green vegetation thus protect the ecosystem by attenuating the noise resulting from traffic and construction (United Nations 2020).

Loss of the green ecosystem according to Treepeople (2020) and UNFAO (2016) exposes the whole ecosystem to direct sun's rays resulting to severe temperature change. Bau-Show and Yann-Jou (2010) and Extension (2019) revealed that the ecosystem can be cooled by trees by as much as $45^{\circ} \mathrm{F}$. Temperature change is a major actor in the sustainability of the ecosystem.

Green ecosystem enhances the quality of fresh air (INSH 2018). Russell (2014); Christopher (2019); Precision Land Scape and Trees (2021) affirmed that trees supply oxygen which is major in the survival of not only man but many living organisms. Oregon Forest Research Institute (OFRI) (2020), Precision Land Scape and Trees (2021) and Russell (2014) observed that from research, a supply of oxygen from an acre of trees can sustain 18 people per day. Thus the quality of air drops where the green ecosystem is absent or depletes (INSH 2018, Extension 2019).

Loss of green ecosystem affects the terrain. According to John (2010); NC State University (2021) and Treepeople (2020), trees are natural water filters. Trees and grasses filter heavy down pour and prevent free flow of storm water thus preventing topography hazards like erosion, landslides and flooding. Voichita (2005) with Treepeople (2020) and UNFAO (2016) agreed that trees protect the soil by absorbing the water that can cause increased run off resulting in higher mud and sediments getting into our water reserves thus making water becoming unsafe for drinking and contaminated for growing foods

Olivia (2018) attested that green ecosystem brings a welcoming environment and that research has shown that there is more violence where there is less green economy. Recreation, relaxation and sports that take the mind from crime and many vices thrives more in green ecosystem like under trees, on green grassland etc. (INSH 2018). Thus, absence of green ecosystem is a breeding medium for crimes of all sorts (Olivia 2018).

Green ecosystem boosts commerce and productivity. Oregon Forest Research Institute (OFRI) (2020), Szaro et al. (1998). Russell (2014), Precision Land Scape and Trees (2021) attested that research has shown that trees grow sales and that for instance, on tree-lined streets consumers shop longer and pay $10 \%$ more for goods. Treepeople (2020) and UNFAO (2016) observed that people tend to be comfortable buying where there are trees, grassland than just open spaces. View of nature according to Christopher (2019) and INSH (2018) has been found to enhance health as workers who do not have a view of nature from their desks call in sick $23 \%$ more often.

\subsection{Conclusions}

Investigation of the depletion of the green ecosystem and its attendant consequences have been the platform upon which the possibility of the protection of the ecosystem and preservation of biodiversity was examined. The wellbeing of the ecosystem is a major factor in the achievement of the Sustainable Development Goals (SDGs), and the protection of the green ecosystem is vital to the survival of the rest ecosystem as it directly affect the man who is the main player in the survival. From the approach of geospatial technology adopted for the study, it was discovered that there was transformations in the land cover of the study area in the year 2002, 2014 and 2018 studied, and a corresponding glaring depletion of duo component the green ecosystem: the thick vegetation $(33.78 \%$, $26.26 \%, 12.18 \%)$ and Light vegetation $(24.57 \%, 32.29 \%, 30.51 \%)$. The transformation in the land cover classes for the two epochs 2002-2014 and 2014-2018 were examined and showed an appreciable gain of $7.17 \%$ and $8.48 \%$ for Built-Up and Bare Land classes respectively at the expense of the thick vegetation (forest) with an overall loss of $21.8 \%$. Light vegetation was observed to 
commence depletion by $1.78 \%$ in the second epoch. These depletion bears generally on the green ecosystem, and the trees are the major actor in the transformation. The alteration and depletion of the green ecosystem and the consequent disappearance of trees is observed to pose very gruesome threat on living and life in general. The sustainability of the environment has become questionable and doubtful, thus endangering the protection of the ecosystem and preservation of the biodiversity. Unstable sustainability of the environment does not guarantee a protected ecosystem or a preserved biodiversity (UNFAO 2020).

Consequent upon the findings in this research and the corresponding grave consequences observed the study hereby recommend that the regulation and control of the removal of the green ecosystem (vegetation) around us should be taken with all seriousness so as to ensure a proper protection of the ecosystem and preservation of the biodiversity. The various consequence of the disappearance of trees should be avoided by the replacement of felled trees and strong afforestation. The ecosystem and biodiversity must be consciously protected and preserved. The soil and the terrain require great preservation from climatic conditions: direct heat from the sun, erosion, flooding and many natural and anthropogenic hazards of the environment. The negative consequences observed and envisaged must be avoided while the positive consequences should embraced at all governmental and most especially individual level. There is need for public education and awareness at all level on the protection of the ecosystem and the preservation of the biodiversity as a matter of urgency, spelling out in clear terms the implication and the benefits to mankind's survival.

\section{References}

Bau-Show, L. and Yann-Jou, L. (2010). Cooling Effect Of Shades Trees With Different Characteristics In a Subtropical Urban Park. American society of horticultural science, 45(1), pp. 8386.

Caballero, P. (2016). A Short History of the SDGs . Available at: https://impakter.com/short-historysdgs/ Accessed: 18th November 2017.

Christopher, B. (2019): Psychology Today-The Neuroscience of Empathy -Neuroscientists identify specific brain areas linked to compassion. Available at: https://www.psychologytoday.com/us/blog/the-athletes-way/201310/the-neuroscience-empathy

Accessed: 9th February 2021.

Extension (2019).Trees For Energy Conservation. Available at: https://trees-energyconservation.org/how-do-trees-cool-the-air/ How do trees cool the air?

Igbokwe, J. I., Ogunlade, S. O., Ejikeme, J. O. and Igbokwe, E. C. (2016). Mapping and Monitoring Deforestation in Ondo State Using Remote Sensing Techniques for Forest Resource Management. Nigerian Journal of Surveying and Geoinformatics, 5(1), pp. 108-117.

INSH (2018). What If Urban Forest Disappear? Backyard Media Inc. Toronto, Ontario M6R 3A9 Canada.

Jamie, O. (2019). What are the four ecosystem Types? Available at: Sciencing. $\mathrm{http} / /$ :sciencing.com/four-ecosystem-types-8102476.hmtl

John, R. (2010).Trees play key role in purifying our water. AJC.com

Keystone Ten Million Trees Partneship (2021): For a Clean Pennsylvani- All about Trees.http://www.tenmilliontrees.org/trees/all about trees Retrieved 9 February 2021

Lackey, R. T. (1998). Seven pillars of ecosystem management. Landscape and Urban Planning, 40 (1-3), pp. 21-30. doi:10.1016/S0169-2046(97)00095-9.

Meffe, G., Nielsen, L., Knight, R. and Schenborn, D. eds. (2013). Ecosystem Management: Adaptive, Community-Based Conservation. Island Press. ISBN 978-1-55963-824-1. 
NC State University (2021): Trees of strength-tree facts. Available at: https://projects.ncsu.edu/project/treesofstrength/treefact.htm. Retrieved 9 February 2021.

Ogunlade, S. O. (2018a). Mapping and Analysis of Spatiotemporal Landuse Dynamics of Akure and Environs, Ondo State Nigeria. [Unpublished Doctoral Desertation]. Nnamdi Azikiwe University, Awka-Nigeria.

Ogunlade, S. O. (2018b). Monitoring the spatial transformation of the Federal University of Technology, Akure between 2002 and 2018: $2^{\text {nd }}$ World Environmental Conservation Conference (WECC)-Transition Pathways to SDGs: Integrated Landscape Approach, Economic Well Being and Inclusive Climate Resilience. $5^{\text {th }}-8^{\text {th }}$ June, 2019 FUTA

Ogunlade, S. O. (2019). Spatiotemporal Landuse Pattern Mapping For Sustainable Development Of Akure City. Journal of Environmental Technology, 1(1), pp. 21-28.

Ogunlade, S. O. (2020a). Decadal Analysis of Land Cover Trend of Federal University of Technology Akure, Ondo State, Nigeria Using Medium Resolution Multi-Temporal Satellite Images. International Journal of Innovative Research \& Development, doi: 10.24940/ijird/2020/v9/i7/JUL20084.

Ogunlade, S. O. (2020b). Site Suitability Mapping For Fish Farming: a Geospatial Approach. 3rd World Environmental Conservation Conference (WECC)- 'Strategies for Improved Quality of Life: Inclusive, Innovative, Integrated and Multi-stakeholder's Participation' Wesley University Ondo, Ondo State, Nigeria. $6^{\text {th }}$ July, 2020

Olivia, W. (2018). Reduce Crime And Violence With Trees In Your Neighbourhood. Winconsin DNR Forestry News., WI DNR Urban Forestry Coordinator, 414-750-8744, Olivia.Witthun@ wisconsin.gov Online.

Oregon Forest Research Institute (OFRI) (2020) Sustainable forest management is key. www.oregonforests.org retrieved on January $25^{\text {th }} 2020$

Oyinloye, M. A., Owoeye, J. O. and Ogunlade, S. O. (2018). Impact of Water Hyacinth on Resident Living in Coastal Areas of Ondo State, Nigeria: A Focus on Ilaje Local Government Area. International Journal of Environmental Monitoring and Protection. 5(3), pp. 52-63.

Precision Land Scape and Trees (2021): 14 fun facts about trees. https://www.precisiontreemn.com/tips/14-fun-facts-about-trees.html Retrieved 9 February 2021

Russell, M. (2014). 21 reasons why forests are important. Mother Nature Network. www.mnn.com/earth-matters/wilderness-resources/blogs/21-reasons-why-forests- are-important

Szaro, R., Sexton, W. T. and Malone, C. R. (1998). The emergence of ecosystem management as a tool for meeting people's needs and sustaining ecosystems. Landscape and Urban Planning, 40(1-3), pp. 1 -7. doi:10.1016/s0169-2046(97)00093-5.

Treepeople (2020).Top 22 benefits of trees https://www.treepeople.org/tree-benefits

UNFAO (2016). Building greener cities: nine benefits of urban trees. www.fao.org

United Nations (2015a). Transforming our world: the 2030 Agenda for Sustainable Development. Sustainable Development Knowledge Platform. (https://sustainabledevelopment.un.org/post2015/transformingourworld)

United Nations (2015b). Sustainable Development Goals 2050. Forests of the future fundamental to achieving Sustainable Development Goals - $\quad$ UN agency. https://www.un.org/sustainabledevelopment/blog/tag/2050/ 
United Nations (2017). Development, World Commission on Environment and. Our Common Future, Chapter 2: Towards Sustainable Development - A/42/427 Annex, Chapter 2 - UN Documents: Gathering a body of global agreements. www.un-documents.net. Retrieved 17 November 2017.

United Nations (2020): Biodiversity and ecosystems https://sustainabledevelopment.un.org/topics/biodiversityandecosystems

Voichita, B. (2005).Urban Forest Acoustics. Pacs 43.28.Fp INRA, Centre de Recherches Forestières de Nancy UMR 1093 - Laboratoire d'Etudes et Recherches sure le Matériau Bois 54280 Champenoux. France. 